\section{Preparation and preclinical evaluation of aceclofenac loaded pectinate mucoadhesive microspheres}

\author{
Santanu Chakraborty, ${ }^{1}$ Priyanka Nayak, ${ }^{1}$ \\ Bala Murali Krishna, ${ }^{1}$ \\ Madhusmruti Khandai, \\ Ashoke Kumar Ghosh ${ }^{3}$ \\ 1Department of Pharmaceutics, College of \\ Pharmaceutical Sciences, ${ }^{2}$ Department of \\ Pharmaceutics, Royal College of \\ Pharmacy and Health Sciences, \\ Berhampur, Orissa; \\ ${ }^{3}$ School of Pharmaceutical Sciences, IFTM \\ University, Moradabad, Uttar Pradesh, \\ India
}

\section{Abstract}

The aim of the present research work was to fabricate aceclofenac loaded pectinate microspheres by ionic gelation method and evaluate the effect of different cross-linking agents and polymer concentration on particle size, encapsulation efficacy and drug release behavior. It was also investigated that whether this pectinate dosage form was able to target the drug release in intestinal region and prevent the different side effect associated with the drug in stomach or not. It was observed that particle size, encapsulation efficacy and in vitro drug release were largely depended on polymer concentration and cross-linking agents. It was also observed that pectinate microspheres showed excellent $\mathrm{pH}$ depended mucoadhesive properties and they were able to restrict the drug release in stomach. In vitro drug release study showed that alminium-pectinate microspheres have more sustaining property as compared to barium-pectinate microspheres. Holm-Sidak multiple comparison analysis suggested a significant difference in measured $t_{50 \%}$ values among all the formulations with same crosslinking agent. In vivo studies revealed that the anti inflammatory and analgesic effects induced by pectinate microspheres were significantly high and prolonged as compared to pure drug. So, pectinate microspheres can be an excellent carrier for targeting the delivery of aceclofenac as well as help in improving the patient compliance by prolonging the systemic absorption.

\section{Introduction}

Natural hydrophilic polymers find wide applications in various pharmaceutical industries for the development of novel drug delivery systems due to their phenomenal properties of low toxicity, biocompatibility and biodegradability. Among these polymers, pectin is widely used in numerous biomedical applications due to their mucoadhesion properties and ability to protect the mucous membrane of the upper gastrointestinal tract from the irritation of chemicals and widely used in pharmaceutical preparations, particularly as a vehicle for controlled drug delivery. ${ }^{1}$ In the controlled release area, mucoadhesive microspheres are one of the most useful devices to deliver materials in an effective, prolonged and safe manner. Among the different natural polysaccharides, biodegradable pectin microspheres offer a novel approach for developing controlled release drug delivery systems that have potential for targeted drug delivery. Pectin is an important ionic polysaccharide derived from plant cell walls contain linear chains of $(1 \rightarrow 4)$ linked $\alpha$-D-galacturonic acid residues. The degree of esterification (DE), which is expressed as a percentage of the esterified carboxyl groups, is an important means to classify pectin. The gelling behaviour of pectin makes it a polymer of choice for drug delivery to the gastrointestinal tract, as matrix tablets, gel beads, film-coated dose form etc.

Aceclofenac is one of the emerging NSAID molecules for arthritis treatment. It is a phenyl acetic acid derivative [2-(2',6'-dichlorophenyl) amino] phenylacetoxyacetic acid], a novel NSAID indicated for the symptomatic treatment of pain and inflammation. ${ }^{2}$ Aceclofenac has a very short biological half-life (about 4 hours) which makes aceclofenac an ideal candidate for prolong release. The high concentration with rapid absorption of aceclofenac causes adverse effect to GIT. To improve the therapeutic efficacy of aceclofenac and reduce the severity of upper GI tract side effect, altering dosage form of aceclofenac can be achieved by modifying release of the formulation to optimize drug delivery.

So, the aim of the present research work was to fabricate aceclofenac loaded pectinate microspheres by using divalent and trivalent cross-linking agents and evaluates the effect of different cross-linking agents and polymer concentration on particle size, encapsulation efficacy and drug release behavior. The ionic gelation technique was selected to prepare barium-pectinate and aluminium-pectinate microspheres due to its simplicity, low cost and high entrapment efficiency of poorly water-soluble drugs. It was also investigated that whether this pectinate microspheres were able
Correspondence: Santanu Chakraborty, PG Department of Pharmaceutics, College of Pharmaceutical Sciences, Mohuda, Berhampur760002, Ganjam, Orissa, India.

Tel. +91.986.126.1608 - Fax: +91.680.222.1331.

E-mail: santanu_nil@rediffmail.com

Key words: pectinate microspheres, aceclofenac, Holm-Sidak multiple comparison analysis, preclinical studies.

Received for publication: 30 September 2011. Revision received: 2 January 2012.

Accepted for publication: 9 Jnauary 2012.

This work is licensed under a Creative Commons Attribution NonCommercial 3.0 License (CC BYNC 3.0).

(C) Copyright S. Chakraborty et al., 2012 Licensee PAGEPress, Italy

Drugs and Therapy Studies 2012; 2:e8 doi:10.4081/dts.2012.e8

to restrict the drug release in GIT and helps to prevent the different side effect or not. Finally preclinical study was conducted to elucidate the anti-inflammatory and analgesic property of these pectinate microspheres system.

\section{Materials and Methods}

\section{Materials}

Aceclofenac (AC) was a gift sample from Nicholas Primal India Ltd, Hyderabad. Pectin (high methoxylated) was a gift from CP Kelco, Denmark. Barium chloride and aluminium sulphate were purchased from Merck. India. Other materials and solvents used were of analytical grade.

\section{Method}

\section{Preparation of microspheres}

Pectin microspheres were prepared by ionic gelation technique by using different crosslinking agents i.e. barium chloride and aluminium sulphate (Table 1). Pectin polymer was dissolved in the pectin solution and stirred for $15 \mathrm{~min}$. This drug containing polymer dispersion was added drop wise to a $5 \%$ (w/v) barium chloride solution (for barium-pectinate microspheres) and aluminium sulphate solution (for aluminium-pectinate microspheres) using a $24 \mathrm{G}$ needle at a constant rate and under continuous stirring at $200 \mathrm{rpm}$. The stirring was continued to $30 \mathrm{~min}$ for complete reaction. After $30 \mathrm{~min}$, all the microspheres were collected by filtration, washed extensively with distilled water and dried overnight at room temperature. Dried microspheres were kept in desiccator for further use. 


\section{Characterization of microspheres}

\section{Physicochemical characterization of Pectinate microspheres}

\section{Percent yield}

The percentage yield of microspheres of various formulations were calculated using the weight of final product (microspheres) after drying with respect to the initial total weight of the drug and polymers used for preparation of microspheres and percentage yield was calculated as per the following formula,

Percentage yield $=\frac{\begin{array}{c}\text { weight of final product } \\ \text { (microspheres) }\end{array}}{\begin{array}{c}\text { weith of the initial raw } \\ \text { materials used in the } \\ \text { formulation } \times 100\end{array}}$

\section{Particle size study}

Size and size distribution of all the microspheres were measured by sieve analysis method. ${ }^{3}$ All the microspheres were separated into different size fractions by sieving using standard sieves (Jayant Scientific Industries, Mumbai, India) of 12, 14, 16, 18 and 22 (mesh apertures i.e. $1.4 \mathrm{~mm}, 1.18 \mathrm{~mm}, 1.0 \mathrm{~mm}, 0.85$ $\mathrm{mm}$ and $0.71 \mathrm{~mm}$ respectively) for $5 \mathrm{~min}$. After 5 min microspheres retained on each sieve were collected separately and weighed. The study was conducted in triplicate and mean particle size of microspheres was calculated using the following formula,

Mean particle size $=$

$\Sigma$ (mean particle size of the fraction $\times$ weight fraction)

इweight fraction

\section{Microencapsulation efficiency}

The entrapment efficiency of the microspheres was determined by the reported method. ${ }^{4}$ The microspheres $(100 \mathrm{mg})$ were allowed to disintegrate in $100 \mathrm{~mL}$ of phosphate buffer (pH 6.8) for $4 \mathrm{~h}$. Dispersion of microspheres was sonicated at $125 \mathrm{~W}$ for $30 \mathrm{~min}$ (Imeco Sonifier, Imeco Ultrasonics, India) and the solution was filtered through whatman filter paper $(0.45 \mathrm{~mm})$. Then, the polymeric debris was washed twice with fresh solvent (phosphate buffer) to extract any adhering drug. The drug content of the filtrate was determined spectrophotometrically at $273 \mathrm{~nm}$ (UV-2450, Shimadzu, Japan). Each determination was made in triplicate and encapsulation efficiency was calculated as follows:

$$
\begin{aligned}
& \text { Entrapment efficiency }(\%)= \\
& \frac{\text { Drug loading }}{\text { Theoretical drug loading }} \times 100
\end{aligned}
$$

\section{Enteric nature of microspheres}

The main side effect of aceclofenac is gastric ulcer and gastric irritation in large dose. Prepared pectinate mucoadhesive microspheres help to prevent the drug release in stomach as well as prevent gastric ulcer and gastric irritation by releasing the drug in intestinal region. So this study was performed to observe whether the drug released from the polymeric matrices in the acidic environment of the stomach or not. ${ }^{5}$ An accurately weighed quantity of microspheres (equivalent to 200 $\mathrm{mg}$ of pure aceclofenac) was soaked in $900 \mathrm{~mL}$ of $0.1 \mathrm{~N} \mathrm{HCl}$ for 2 hours at $37 \pm 0.5^{\circ} \mathrm{C}$ in a water bath. Then the sample was centrifuged at 2000 rpm for $20 \mathrm{~min}$ and analysed by UV-spectrophotometer at $273 \mathrm{~nm}$ for determination of aceclofenac concentration.

\section{Mucoadhesion studies of microspheres}

The mucoadhesion property of the microsphere was assessed by in vitro wash-off test. ${ }^{6}$ The test was performed in both $0.1 \mathrm{~N} \mathrm{HCl}$ and phosphate buffer, $\mathrm{pH} 6.8$. The freshly excised pieces of goat intestinal mucosa $(2 \times 3 \mathrm{~cm})$ were mounted onto glass slides with cyanoacrylate glue. About 50 no. of microspheres were spread onto each wet rinsed tissue specimen and immediately thereafter the slides were hung onto the arm of a USP tablet disintegrating test apparatus. The tissue specimen was placed in a vessel containing one liter fluid at $37^{\circ} \mathrm{C}$ and given a slow and regular up-down movement. At predetermined time interval, the number of microspheres still adhering to the tissue was counted and the adhering percent was calculated by the following formula,

Adhesion (\%)=

number of microspheres adhered number of microspheres applied $\times 100$

\section{In vitro drug release study}

Drug release from the prepared microspheres was determined by using six stage USP dissolution rate test apparatus II (DISSO 2000, LABINDIA, India). An accurately weighed quantity of microspheres (equivalent to 200 $\mathrm{mg}$ of pure aceclofenac) and marketed aceclofenac SR tablet (equivalent to $200 \mathrm{mg}$ of pure aceclofenac) was placed in dissolution flask containing $900 \mathrm{~mL}$ of $0.1 \mathrm{~N} \mathrm{HCl}$ for 2 hours, followed by phosphate buffer, $\mathrm{pH} 6.8$ for the remaining hours. ${ }^{7}$ The dissolution medium was stirred at $50 \mathrm{rpm}$ and maintained to a constant temperature $37 \pm 0.5^{\circ} \mathrm{C} .5 \mathrm{~mL}$ samples were withdrawn at predetermined time interval and analyzed for aceclofenac content using UV-Visible double beam spectrophotometer (UV-2450 Shimadzu, Japan) at $273 \mathrm{~nm}$. The release studies were conducted in triplicate.

\section{Analysis of release profiles}

The rate and mechanism of drug release from the prepared microspheres were analyzed by fitting the dissolution data into different rate equations such as:

Zero order equation, ${ }^{8}$

$$
\mathrm{Q}=\mathrm{k}_{0} \mathrm{t}
$$

Where, $Q$ is the amount of drug released at time $t$ and $k_{0}$ is the zero order release rate constant.

First order equation, ${ }^{9}$

$$
\ln (100-0)=\ln 100-k_{1} t
$$

where $k_{1}$ is the first order release rate constant.

Higuchi's square root model,,${ }^{10}$ which primarily describes the drug release from a heterogeneous matrix where the drug is dispersed uniformly and the drug diffuses out from the hydrated or solvated polymer matrix as:

$$
\mathrm{Q}=\mathrm{k}_{\mathrm{H}} \mathrm{t}^{1 / 2}
$$

Where, $Q$ is the percentage of drug released at time $t, k_{H}$ is the Higuchi release rate constant. Hixson-Crowell rate equation, ${ }^{11}$

$$
3 \sqrt{Q_{0}}-3 \sqrt{Q_{t}}=K_{H C t}
$$

Where, $Q_{t}$ is the amount of drug released in time $t, Q_{0}$ is the initial amount of the drug in the formulation and $\mathrm{K}_{\mathrm{HC}}$ is the release rate constant for the Hixson-Crowell rate equation. Higuchi equation and Hixson-Crowell rate equation sometimes fails to explain drug release mechanism due to swelling (upon hydration) along with gradual erosion of the matrix. Therefore, the dissolution data was also fitted to the well-known exponential equation (Peppas equation), which is often used to describe the drug release behavior from polymeric system.

Peppas equation, ${ }^{12-13}$

$$
\frac{\mathrm{M}_{\mathrm{t}}}{\mathrm{M} \infty}=\mathrm{kt} \mathrm{t}^{\mathrm{n}}
$$

Where, $\mathrm{n}$ is the release exponent; indicative of the mechanism of release, $\mathrm{M}_{t} / \mathrm{M}_{\infty}$ is the fraction of the drug at time $\mathrm{t}, \mathrm{K}$ is the release rate constant.

The criteria for selecting the most appropriate model were based on the highest values of the coefficient of determination $\left(\mathrm{r}^{2}\right)$.

\section{Similarity Factor $\left(f_{2}\right)$}

The dissolution profile comparison of prepared microsphere formulations and marketed product may be carried out using model independent approach i.e. similarity factor $\left(\mathrm{f}_{2}\right)$. The similarity factor $\left(\mathrm{f}_{2}\right)$ represents closeness of two comparative formulations. Generally similarity factor in the range of 50 to 100 is acceptable according to US FDA and can be calculated by using following formula, ${ }^{14}$

$$
\mathrm{f}_{2}=50 * \log \left\{\left[1+(1 / \mathrm{n}) \Sigma_{\mathrm{t}=1}^{\mathrm{n}}\left(\mathrm{R}_{\mathrm{t}}-\mathrm{T}_{\mathrm{t}}\right)^{2}\right]^{-0.5 * 100}\right\}
$$

$f_{2}$ is the similarity factor, $n$ is the number of time point, $R_{t}$ is the mean percent drug dissolved of reference product and $T_{t}$ is the mean percent drug dissolved of test product.

\section{Scanning electron microscopy}

Shape and surface morphology of microspheres were studied by using scanning elec- 
tron microscope (JOEL SEI. Japan). The sample was placed in the scanning electron microscope chamber at acceleration voltage of $20 \mathrm{kV}$ and chamber pressure of $0.6 \mathrm{~mm} \mathrm{Hg}$ Photographs were taken at different magnification (X 40, X 100, X 200 and X 750) and shown in Figure 5A-5D.

\section{Fourier Transform Infrared Analysis analysis}

Fourier Transform Infrared Analysis (FTIR) of pure drug, pure polymer and optimized microsphere formulation was obtained using FTIR analyzer (Prestige-21, Shimadzu FT-IR, Japan). The samples were scanned over the wave number ranges between 4000 to $400 \mathrm{~cm}^{-1}$ at the ambient temperature and shown in Figure 1.

\section{Differential scanning calorimetric analysis}

Differential Scanning Calorimetric (DSC) thermograms of pure drug (aceclofenac), pure polymer and optimized microsphere formulations were obtained using a Differential Scanning Calorimeter (Diamond DSC, PYRIS, Perkin Elmer, USA). The samples were hermetically sealed in perforated aluminum pans and heated at constant rate of $10^{\circ} \mathrm{C} / \mathrm{min}$ over a temperature range of $50^{\circ} \mathrm{C}$ to $400^{\circ} \mathrm{C}$ and shown in Figure 2.

\section{In vivo study}

In vivo study was carried out with respect to anti-inflammatory activity and analgesic activity of the prepared microspheres and the results were compared with pure drug and marketed formulation. The anti-inflammatory study was carried out in male Wistar rats (weighing 180-200 g) and analgesic study was carried out in Male Swiss albino mice (25-30 g) obtained from the Central Animal House, College of Pharmaceutical Sciences, Berhampur, Orissa, India. The animals were housed in standard environmental condition $\left(25 \pm 1^{\circ} \mathrm{C} ; 55 \pm 5 \%\right.$ relative humidity and $12 / 12 \mathrm{~h}$ light dark cycle lighting) in elevated wire cages (4 animals per cage) with free access to food (Lipton Feed, India) and water. The study protocol was approved by the Institutional Animal Ethical Committee, College of Pharmaceutical Sciences, Berhampur, Orissa, India (Approval No: 1170/ac/08/CPCSEA).

\section{Anti-inflammatory activity}

Carrageenan- induced rat paw edema model ${ }^{15}$ was used to study the anti-inflammatory effect of pure drug, optimized microsphere formulations and commercial aceclofenac SR tablet. ${ }^{16}$ The overnight fasted animals were divided into 4 groups $(\mathrm{n}=6)$ and treated as follows:

Group I (control): $2.5 \mathrm{~mL}$ of $0.5 \%$ sodium carboxymethylcellulose; p.o.

Group II: Pure aceclofenac $(10 \mathrm{mg} / \mathrm{kg})$ in $0.5 \%$ sodium carboxymethylcellulose; p.o.

Group III: Optimized microsphere formulation (equivalent to $10 \mathrm{mg} / \mathrm{kg}$ of pure aceclofenac) in $0.5 \%$ sodium carboxymethylcellulose; p.o.

Group IV: Commercial aceclofenac SR tablet, Aristo, India (equivalent to $10 \mathrm{mg} / \mathrm{kg}$ of pure aceclofenac) in $0.5 \%$ sodium carboxymethylcellulose; p.o.

After 30 min of drug administration, rats of all groups were challenged by a subcutaneous injection of $0.1 \mathrm{~mL}$ of $1 \%$ solution of carrageenan in saline into the plantar site of the left hind paw. The paw volumes were measured with a plethysmometer (Digital rat paw plethysmograph, INCO, India), prior to administration of carrageenan and after $1,2,3,4,5$, 6,7 and 8 hours of administration. The percent inhibition of edema for all time intervals were calculated using the following formula,

$$
\text { Inhibition }(\%)=\frac{\left(V_{c}-V_{t}\right)}{V_{c}} \times 100
$$

Where $V_{c}$ represent mean paw volume of con-

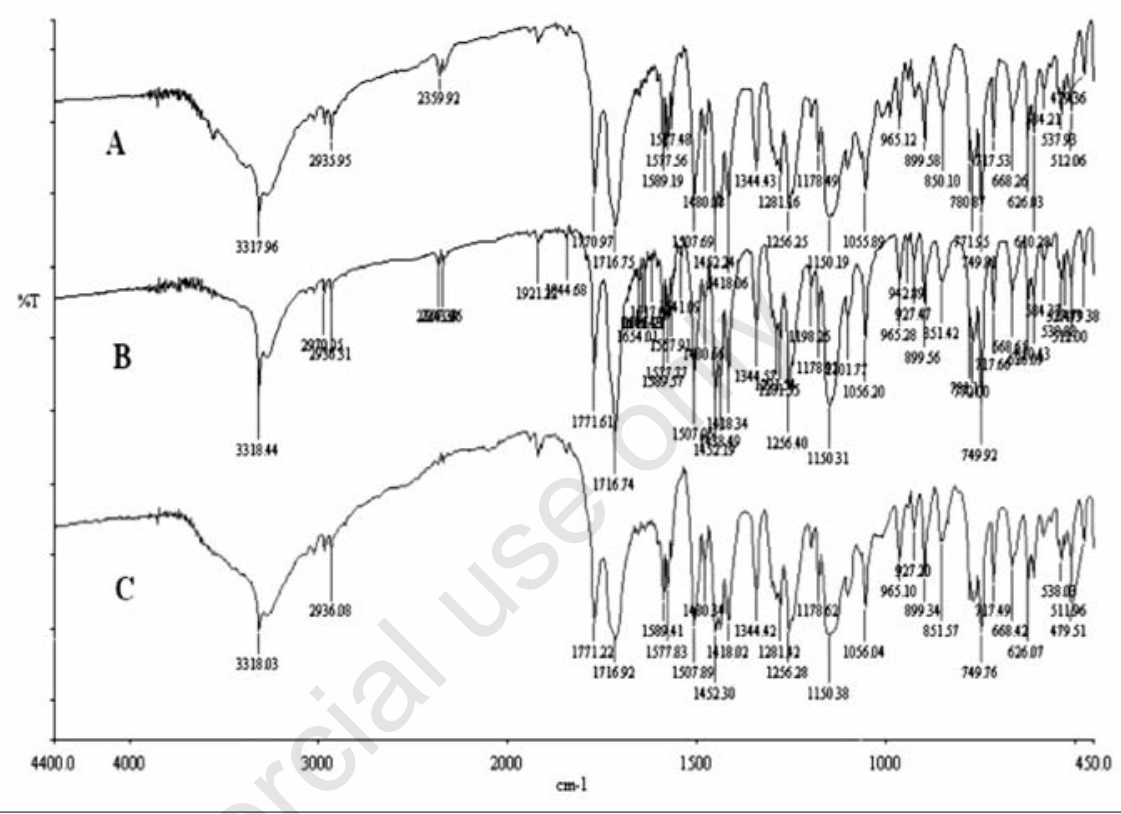

Figure 1. Fourier Transform Infrared Analysis spectra of aceclofenac (A), pectin (B), optimized microsphere formulation $(\mathrm{C})$.

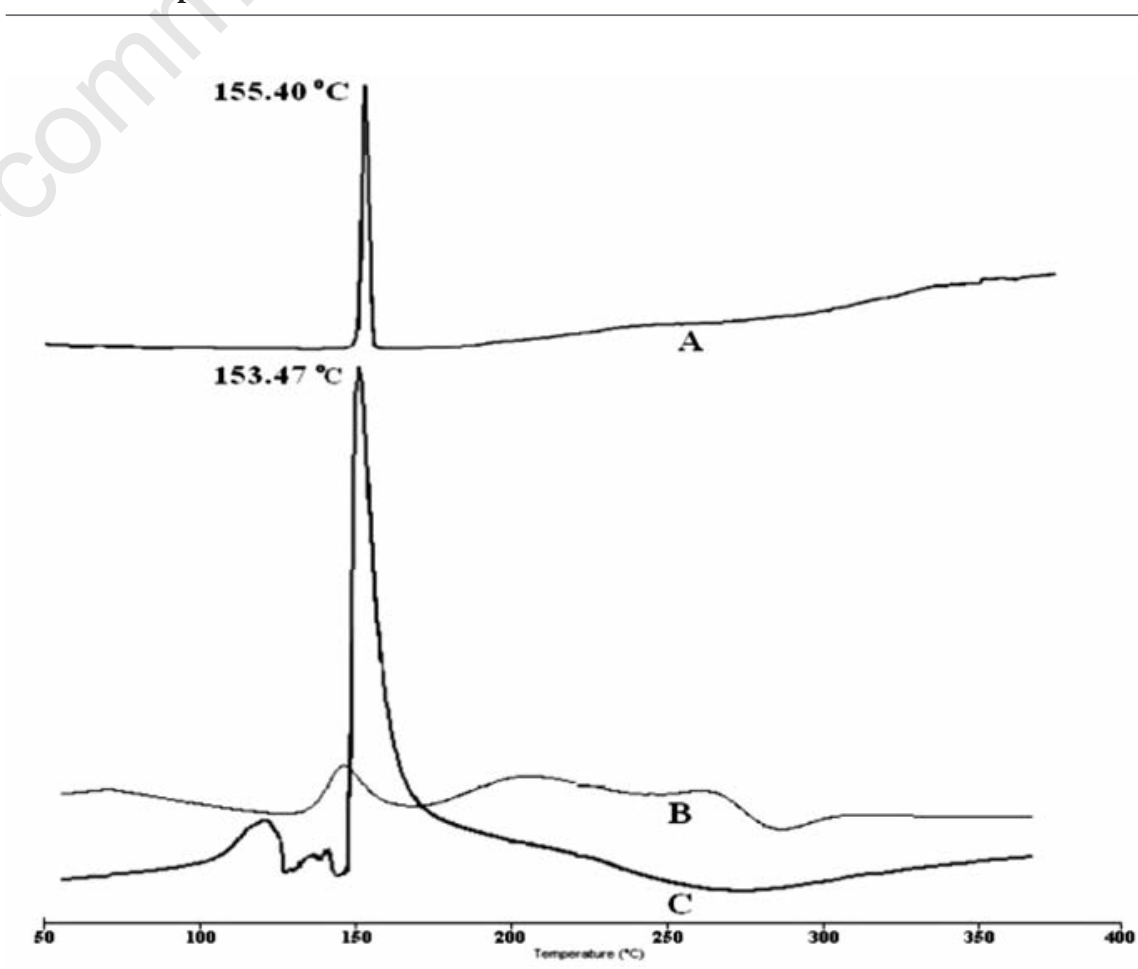

Figure 2. Differential scanning calorimetric thermodram of pure aceclofenac (A), pectin (B), optimized Formulation (C). 
trol group and Vt represent mean paw volume of test group.

\section{Analgesic activity}

Writhing test was used to study the analgesic activity of pure drug, optimized microsphere formulations and commercial aceclofenac SR tablet. ${ }^{17}$ Male Swiss albino mice $(25-30 \mathrm{~g})$ were used for the study. The overnight fasted animals were divided into 4 groups ( $\mathrm{n}=6)$ and treated as follows:

Group I (control): $2.5 \mathrm{~mL}$ of $0.5 \%$ sodium carboxymethylcellulose; p.o.

Group II: Pure aceclofenac (10 mg/kg) in $0.5 \%$ sodium carboxymethylcellulose; p.o.

Group III: Optimized microsphere formulation (equivalent to $10 \mathrm{mg} / \mathrm{kg}$ of pure aceclofenac) in $0.5 \%$ sodium carboxymethylcellulose; p.o. Group IV: Commercial aceclofenac SR tablet (equivalent to $10 \mathrm{mg} / \mathrm{kg}$ of pure aceclofenac) in $0.5 \%$ sodium carboxymethylcellulose; p.o.

After 1 hour, mice of all groups were challenged by an intraperitoneal injection of $1 \%$ acetic acid solution $(0.1 \mathrm{~mL}$ per $10 \mathrm{~g})$. Then the number of writhing was recorded for 4 hour. The analgesic activity was evaluated in terms of the percentage of writhe inhibitions.

\section{Statistical analysis}

In vitro drug release data of all the formulations were subjected to one way analysis of variance (one way ANOVA) followed by HolmSidak multiple comparison analysis to find out any significant difference. Statistical analysis of the data was performed using the PRISM software (Graph pad, San Diego, CA). A confidence limit of $\mathrm{P}<0.05$ was fixed for interpretation of the results.

\section{Results and Discussion}

\section{Physicochemical characterization of pectinate microspheres}

The percentage yield of the different pectinate microsphere formulations was found to be in the range of $88.34 \pm 5.34 \%$ to $96.44 \pm 5.67 \%$ for barium-pectinate microspheres and $84.38 \pm 3.99 \%$ to $94.27 \pm 4.38 \%$ for aluminiumpectinate (Table 1). The percentage entrapment efficiency and particle size were found within the range of $38.27 \pm 4.44 \%$ to $66.39 \pm 4.20 \%$ and $467 \pm 7.79 \mu \mathrm{m}$ to $567 \pm 6.62$ $\mu \mathrm{m}$ for barium-pectinate microspheres whereas in case of aluminium-pectinate, percentage entrapment efficiency and particle size were found within the range of $61.90 \pm 2.22 \%$ to $79.55 \pm 3.81 \%$ and $715 \pm 5.59 \mu \mathrm{m}$ to $873 \pm 6.02$ $\mu \mathrm{m}$ respectively. It was found from the experiment that percentage entrapment efficiency increased with increase in polymer concentration (Table 1) which may be due to higher concentration of the polymer may increases the viscosity of the medium and hence, increases availability of cross-linking binding sites in the polymeric chains, as a result the degree of cross-linking may be enhanced ${ }^{18}$ and larger droplets were formed which entrapping greater amount of drug in the microspheres.

\section{Enteric nature of microspheres}

Study of enteric nature of the prepared microspheres helps to evaluate the ability of the prepared formulations to restrict the drug release in the acidic environment to reduce the side effect or not. It was observed that in $0.1 \mathrm{~N} \mathrm{HCl}$ medium ( $\mathrm{pH} 1.2$ ), barium-pectinate microspheres i.e. formulation BP1 to BP4 shows $13.58 \pm 4.46 \%$ to $8.43 \pm 3.66 \%$ drug release whereas aluminium-pectinate formulations (AP1 to AP4) shows $11.06 \pm 2.34 \%$ to $5.86 \pm 1.47 \%$ drug release in 2 hours. This may be due to the amount of aceclofenac which was present on the surface of the microspheres, immediately comes in contact with the medium. Barium-pectinate microspheres shows more amount of drug was release in acidic media as compare with aluminium-pectinate which may results due to formation of more rigid coat with trivalent ion as compared to divalent $\mathrm{Ba}^{2+}$ ion. As a result leaching out effect was more prominent for barium-pectinate microspheres. Though very less amount of drug was released in case of aluminiumpectinate formulation AP2 to AP4 $(5.86 \pm 1.47 \%$ to $9.47 \pm 3.49 \%$ ) in acidic medium, these crosslinked polymer may be able to protect the acidlabile drug as well as protect gastric mucosa from adverse effect of drug.

\section{Mucoadhesion studies of microspheres}

The mucoadhesive properties of prepared microspheres containing pectin being studied with in-vitro wash-off test. It was found that all the microspheres have less mucoadhesion property in simulated gastric fluid ( $\mathrm{pH} 1.2)$ in compared to simulated intestinal fluid ( $\mathrm{pH}$ 6.8). It was observed that all formulations in intestinal fluid (pH 6.8 buffer solution) exhibited

Table 1. Formulation and physicochemical characterization of the aceclofenac-loaded pectin microspheres.

\begin{tabular}{lccccc}
$\begin{array}{l}\text { Formulation } \\
\text { code }\end{array}$ & $\begin{array}{c}\text { Drug: } \\
\text { polymer }\end{array}$ & $\begin{array}{c}\text { Cross-linking } \\
\text { agent } \\
(5 \% w / v)\end{array}$ & $\begin{array}{c}\text { Yield } \\
(\%)\end{array}$ & $\begin{array}{c}\text { Entrapment } \\
\text { Efficiency } \\
(\%)\end{array}$ & $\begin{array}{c}\text { Particle } \\
\text { sive } \\
(\text { um })\end{array}$ \\
BP1 & $1: 1$ & $\mathrm{BaCl}_{2}$ & $88.34 \pm 5.34$ & $38.27 \pm 4.44$ & $467 \pm 7.79$ \\
BP2 & $1: 2$ & $\mathrm{BaCl}_{2}$ & $90.12 \pm 3.29$ & $43.26 \pm 3.28$ & $482 \pm 5.37$ \\
\hline BP3 & $1: 3$ & $\mathrm{BaCl}_{2}$ & $93.28 \pm 3.28$ & $54.45 \pm 5.82$ & $541 \pm 10.2$ \\
BP4 & $1: 4$ & $\mathrm{BaCl}_{2}$ & $96.44 \pm 5.67$ & $66.39 \pm 4.20$ & $567 \pm 6.62$ \\
\hline AP1 & $1: 1$ & $\mathrm{Al}_{2}\left(\mathrm{SO}_{3}\right)$ & $84.38 \pm 3.99$ & $61.90 \pm 2.22$ & $715 \pm 5.59$ \\
AP2 & $1: 2$ & $\mathrm{Al}_{2}(\mathrm{SO})_{3}$ & $89.04 \pm 4.01$ & $68.37 \pm 8.90$ & $762 \pm 8.12$ \\
\hline AP3 & $1: 3$ & $\mathrm{Al}_{2}(\mathrm{SO})_{3}$ & $92.37 \pm 5.47$ & $75.97 \pm 4.18$ & $811 \pm 4.47$ \\
AP4 & $1: 4$ & $\mathrm{Al}_{2}(\mathrm{SO} 4)_{3}$ & $94.27 \pm 4.38$ & $79.55 \pm 3.81$ & $873 \pm 6.02$ \\
\hline
\end{tabular}

Mean $\pm S D, n=3$. BP, Barium-pectinate microspheres; AP, aluminium-pectinate formulations.
$46.58 \pm 2.40 \%$ to $92.89 \pm 4.08 \%$ mucoadhesion up to 6 hours (Figure $3 \mathrm{~A}$ ) whereas $2.07 \pm 1.09 \%$ to $4.16 \pm 0.93 \%$ mucoadhesion was observed up to 6 hours (Figure 3B) in pH 1.2 buffer solution. The results indicate that the pectin was practically insoluble in aqueous acidic solution, whereas in phosphate buffer its solubility, hydration and mucoadhesivity property was increased due to ionization of carboxylic acid group and other functional groups present in the polymer. This ionization of functional groups in simulated intestinal fluid helps to increase polymer solubility in turn to produce a viscous gel which increases the mucoadhesion property.

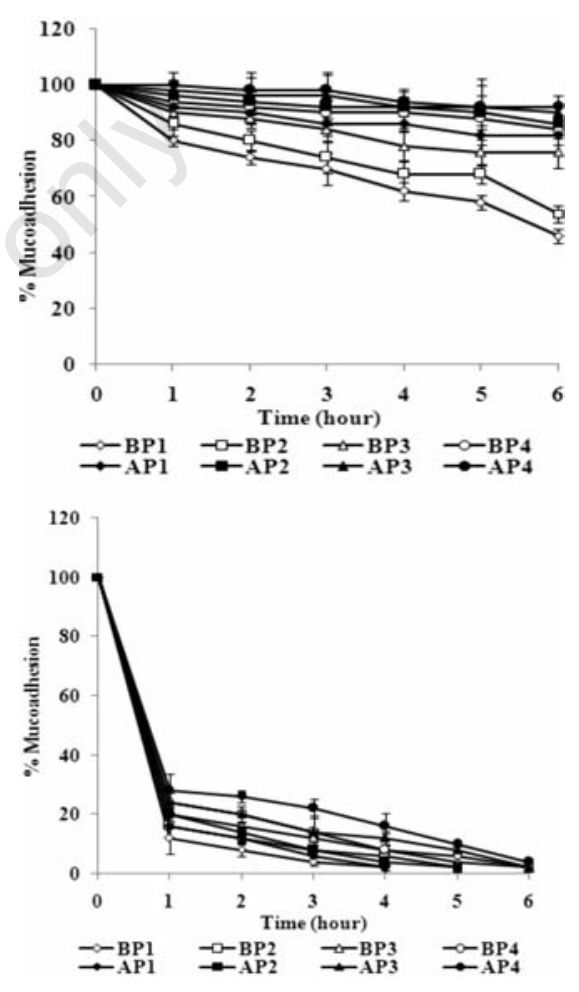

Figure 3. Mucoadhesion behavior of pectinate microspheres in $A$ ) phosphate buffer (pH 6.8) and $\mathrm{B}$ ) in $0.1 \mathrm{~N} \mathrm{HCL}(\mathrm{pH} \mathrm{1.2).}$ 


\section{In vitro drug release studies}

The effect of polymer concentration on the release of aceclofenac from pectin microspheres was studied using USP six stage dissolution rate test apparatus (Figure 4). It was observed that for all the formulations very less amount of drug was released in $0.1 \mathrm{~N} \mathrm{HCl}$ within 2 hours whereas in phosphate buffer medium all the formulations shows a fast release within 2 hours followed by slow release for remaining hours. At lower $\mathrm{pH}$, ionisation of the carboxylate groups present in pectin is suppressed, and this results in a reduction in hydration of the carboxylic acid groups. As a result of reduced ionisation, the polysaccharide molecules no longer repel each other over their entire length. So at low $\mathrm{pH}$, the formation of pores was very low and the polysaccharide molecules can associate themselves and maintain their rigidity. At higher $\mathrm{pH}$, the chain cleavage of polysaccharide molecules was taking place. As a result the polymeric coat loss their viscosity and gelling properties very rapidly and allow faster drug release.

It was found that the polymer concentration of the prepared microspheres increased; result in decrease the drug release proportionately. It may be due to an increase in the densities of the polymer matrix resulting in larger microspheres and this in turn increases the diffusion path length, which the drug molecules have to traverse.

Barium-pectinate microspheres (BP1 to BP4) were able to sustain the drug released up to $6,8,9$ and 10 hours respectively whereas aluminium-pectinate microspheres were able to sustain the drug released up to 8,10 and 12 hours. It has been observed that barium-pectinate microsphere showed comparatively rapid drug release as compared to aluminium-pectinate formulations. It may be due to the fact

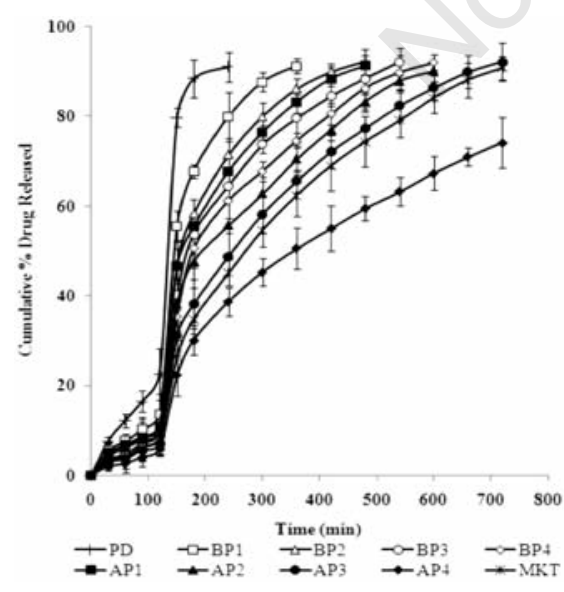

Figure 4. Drug release profile of pure drug (PD), pectinate microspheres and marketed formulation (MKT). that barium being divalent, form two-dimensional bonding structure with pectin whereas aluminium (trivalent) could form threedimensional bonding structure with the pectin inside the microspheres. This three-dimensional bonding results in extended cross-linking through the whole microsphere producing hard aluminium-pectinate microspheres with low water uptake and thus leading to slow removal of $\mathrm{Al}^{3+}$ due to ion-exchange with $\mathrm{Na}^{+}$ in the phosphate buffer. As a result, the swelling of the microspheres were delayed leading to slow disintegration as well as slow dissolution.

Subsequently increasing the concentration of pectin and alteration in cross-linking agent, prolonged the drug release was observed up to 12 hours because pectin could form more rigid coat with trivalent $\left(\mathrm{Al}^{3+}\right)$ ion as compared to divalent $\left(\mathrm{Ba}^{2+}\right)$. The free carboxylic groups in the HM pectin molecule are distributed blockwise; therefore the gelation of this pectin is possible because of the egg-box structure, resulting from chelation of barium and aluminium ions in electronegative cavities formed by the carboxyl residues and hydroxyl groups. ${ }^{19}$

One way analysis of variance suggested a significant difference in $t_{50}$ value at $P<0.05$ among all the barium-pectinate formulations and among all the aluminium-pectinate formulations. Holm-Sidak multiple comparison analysis suggested a significant difference among all the formulations with respect to in vitro drug release (except AP3 and MKT). Formulation AP3 shows the best dissolution profile (more than $90 \%$ drug was released in 12 hours) and multiple comparison analysis suggested that this formulation have no significant difference with marketed formulation with respect to in vitro drug release.
The kinetic data of all the formulations shows best fit in first order kinetics model followed by Fickian diffusion mechanism. The kinetic data of pure drug and marketed formulation shows best fit in Hixson-Crowell model $\left(r^{2}=0.997\right)$ and Higuchi model $\left(r^{2}=0.998\right)$ respectively. The $t_{50 \%}$ value of the optimized microspheres formulation (AP3) was 4.27 hours. All the kinetics datas are summarized in Table 2.

\section{Similarity factor $\left(f_{2}\right)$}

The model independent method such as similarity factor $\left(\mathrm{f}_{2}\right)$ provides a simple way to compare dissolution data. US FDA guidance proposes that $\mathrm{f}_{2}$ values of 50 to 100 indicate equivalence in dissolution profiles. The similarity factor $\left(\mathrm{f}_{2}\right)$ values of all the pectinate microsphere formulations were 14.17 to 81.72 . Among all the formulations, only AP3 shows the $f_{2}$ value $>50$ (AP3, 81.72), indicates that the drug release of this formulation was similar with the drug release of marketed formulations and there was no significant difference between AP3 and marketed formulation with respect to their dissolution profiles. So AP3 has selected as optimized formulation for further studies.

\section{Scanning electron microscopy}

The surface morphology was studied through scanning electron microscope. The scanning electron micrographs (SEM) of different magnification are shown in Figure 5 The SEM study revealed that all the aceclofenac loaded pectinate microspheres were discrete and almost spherical in shape. At higher magnification (i.e. 200 and 750), it was observed that surface of the microsphere was rough (Figure 5C and 5D). This might be due to the density of the polymer matrix which in turn justifies its sustained release.

Table 2. Kinetics of drug release from aceclofenac microspheres (Analyzed by the regression coefficient method).

\begin{tabular}{|c|c|c|c|c|c|c|c|}
\hline \multirow[t]{2}{*}{ Formulations } & \multicolumn{5}{|c|}{$\begin{array}{l}\text { Coefficient of determination } \\
\qquad\left(\mathrm{r}^{2}\right)\end{array}$} & \multirow{2}{*}{$\begin{array}{c}\text { Release } \\
\text { exponent } \\
\text { (n) }\end{array}$} & \multirow[t]{2}{*}{$\begin{array}{c}\mathrm{t}_{50 \%} \\
\text { (hour) }\end{array}$} \\
\hline & $\begin{array}{l}\text { Zero } \\
\text { Order }\end{array}$ & $\begin{array}{l}\text { First } \\
\text { Order }\end{array}$ & $\begin{array}{l}\text { Higuchi } \\
\text { Model }\end{array}$ & $\begin{array}{c}\text { Hixson- } \\
\text { Crowell } \\
\text { Model }\end{array}$ & $\begin{array}{l}\text { Korsmeyer } \\
\text { Model }\end{array}$ & & \\
\hline PD & 0.843 & 0.898 & 0.908 & 0.997 & 0.837 & - & 2.13 \\
\hline BP1 & 0.902 & 0.989 & 0.976 & 0.911 & 0.976 & 0.49 & 2.47 \\
\hline $\mathrm{BP} 2$ & 0.916 & 0.993 & 0.957 & 0.864 & 0.986 & 0.42 & 2.70 \\
\hline BP3 & 0.905 & 0.991 & 0.978 & 0.821 & 0.989 & 0.34 & 2.87 \\
\hline $\mathrm{BP} 4$ & 0.914 & 0.994 & 0.990 & 0.797 & 0.992 & 0.46 & 2.98 \\
\hline AP1 & 0.926 & 0.991 & 0.982 & 0.921 & 0.985 & 0.39 & 2.72 \\
\hline $\mathrm{AP2}$ & 0.933 & 0.994 & 0.990 & 0.867 & 0.984 & 0.32 & 3.30 \\
\hline AP3 & 0.945 & 0.996 & 0.987 & 0.851 & 0.990 & 0.38 & 4.27 \\
\hline $\mathrm{AP} 4$ & 0.959 & 0.995 & 0.992 & 0.882 & 0.986 & 0.41 & 4.90 \\
\hline MKT & 0.932 & 0.957 & 0.998 & 0.785 & 0.991 & 0.37 & 4.38 \\
\hline
\end{tabular}

PD, pure aceclofenac; BP, Barium-pectinate microspheres; AP, aluminium-pectinate formulations; MKT, marketed formulation. 


\section{Fourier transform infrared analysis analysis}

To study the drug-excipients interactions, the infrared spectrum of pure drug (aceclofenac), pure polymer (pectin) and the optimized formulation (AP3) containing both the drug and polymer were scanned and shown in Figure 1. Pure aceclofenac showed different peaks at 3317.9, 1770.9, 1716.7, 1589.1, 1507.6, 1344.4, 1281.1 and $1055.8 \mathrm{~cm}^{-1}$. Among them some major peaks are 3317.9 for stretching vibration of $\mathrm{OH}$ of $\mathrm{COOH}$ group, 1716.7 for stretching vibration of $\mathrm{C}=0$ attached to the methylene group and ether, 1281.1 for C-N stretching vibration of secondary aromatic amine, 1055.8 for $\mathrm{OH}$ bending vibration. ${ }^{5}$ In the optimized microsphere formulation (AP3), all the above mentioned peaks were intact indicating no interaction between drug and polymers.

\section{Differential scanning calorimetric analysis}

In the present investigation, DSC thermograms of pure drug, pure polymer and optimized microspheres (formulation AP3) were taken and shown in Figure 2. It was observed that pure aceclofenac exhibited prominent melting endotherm at $155.40^{\circ} \mathrm{C}$ whereas optimized microsphere formulation (AP3) shows a melting endotherm at $153.47^{\circ} \mathrm{C}$, indicating no considerable change in melting endotherm of the drug. The broadening of the endotherm peak may be due to the presence of polymers in
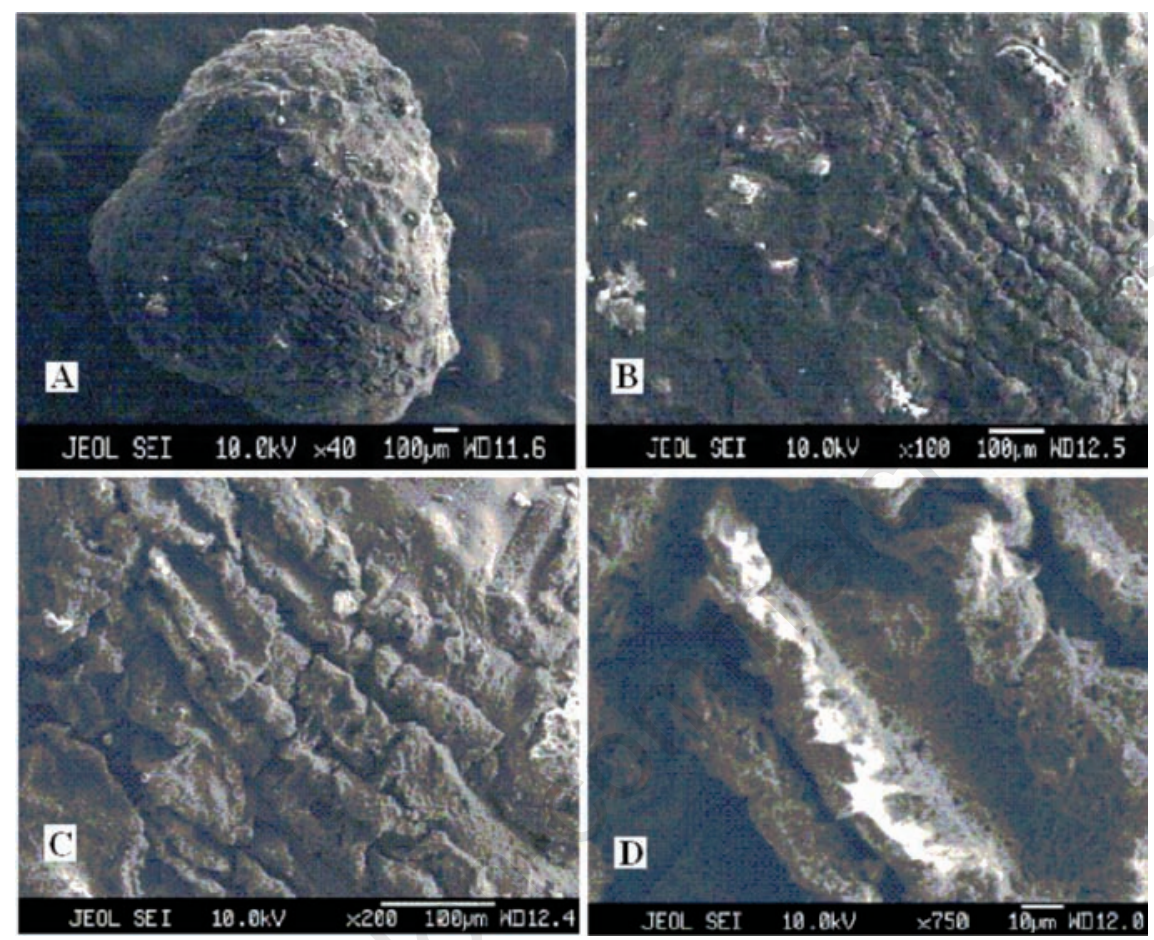

Figure 5. Scanning electron photomicrographs of pectinate microspheres of formulation AP3 (optimized formulation) A) $40 \mathrm{X}, \mathrm{B}) 100 \mathrm{X}, \mathrm{C}) 200 \mathrm{X}, \mathrm{D}) 750 \mathrm{X}$.

Table 3. Effect of aceclofenac on the paw edema induced by carrageenan in wistar rats.

\begin{tabular}{lccc} 
Time (hour) & \multicolumn{3}{c}{ \% Inhibition } \\
\hline 0 & - & AP3 & MIKT \\
1 & $56.49 \pm 4.31$ & - & - \\
\hline 2 & $72.32 \pm 6.95$ & $17.21 \pm 4.97^{*}$ & $15.13 \pm 6.89^{*}$ \\
3 & $81.36 \pm 7.77$ & $28.34 \pm 5.82^{*}$ & $22.39 \pm 5.63^{*}$ \\
\hline 4 & $88.02 \pm 5.48$ & $56.12 \pm 7.91^{*}$ & $45.93 \pm 7.87^{*}$ \\
5 & - & $73.23 \pm 4.90^{*}$ & $65.04 \pm 4.28^{*}$ \\
\hline 6 & - & $81.13 \pm 5.97^{*}$ & $78.44 \pm 7.86^{*}$ \\
7 & & $88.02 \pm 7.98^{*}$ & $86.42 \pm 5.80^{*}$ \\
\hline 8 & & $90.01 \pm 7.64^{*}$ & $89.90 \pm 3.91^{*}$ \\
\hline All values are expressed as Mean \pm SD, $\mathrm{n}=6 ;$ PD, Pure aceclofenac; AP3, optimized aluminium-pectinate formulations; MKT, Marketed tablet. \\
*Significant difference compared to PD (P<0.05).
\end{tabular}

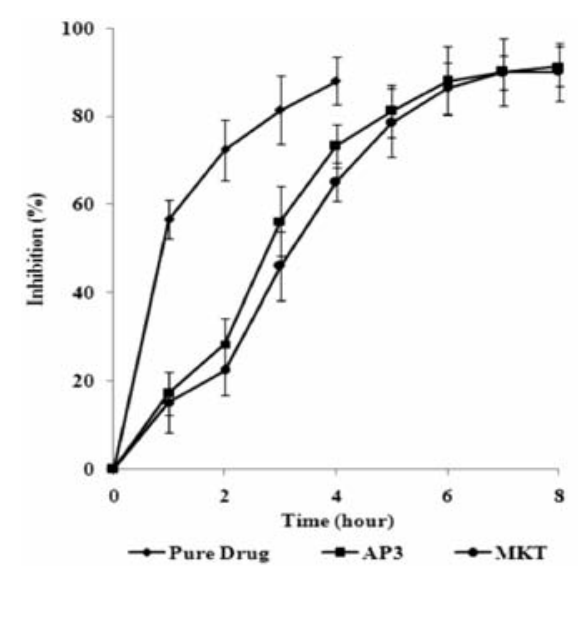

Figure 6. Anti-inflammatory activity study of pure drug, optimized microspheres (AP3) and marketed formulation (MKT). 
tions and $52.27 \pm 4.37 \%$ contractions inhibition. At the same time marketed formulation shows $13.67 \pm 1.92$ no. of contractions and 58.36 $\pm 6.62 \%$ contractions inhibition. The results indicate that the optimized microspheres (AP3) and commercial SR tablet produce sustained action of aceclofenac.

So, it was observed from the above research work that different cross-linking agents and polymer concentration have greatly effect the particle size, encapsulation efficacy and drug release behavior. It was also observed that these pectinate microspheres were able to restrict the drug release in GIT as well as helps to prevent the different side effects. Preclinical data clearly elucidate that prepared pectinate microspheres shows good anti-inflammatory and analgesic property for prolong period of time. Finally, it is concluded that ionic gelation technique can be used to prepare bariumpectinate and aluminium-pectinate microspheres and aluminium-pectinate formulation can widely used for targeted drug delivery.

\section{References}

1. Bodmeier R, Wang J. Microencapsulation of drugs with aqueous colloidal polymer dispersions. J Pharm Sci 1993;82:191-94.

2. Lipman AG. Martindale: the Extra Pharmacopoeia. 30th ed. London: The Pharmaceutical press; 1993.

3. Viswanathan NB, Thomas PA, Pandit JK, et al. Preparation of non-porous microspheres with high entrapment efficiency of proteins by a (water-in-oil)-in-oil emul- sion technique. J Control Rel 1999;58:9-20.

4. Agnihotri SA, Jawalkar SS, Aminabhavi TM. Controlled release of cephalexin through gellan gum beads: Effect of formulation parameters on entrapment efficiency, size, and drug release. Eur J Pharm Biopharm 2006;63:249-61.

5. Chakraborty S, Khandai M, Sharma A, et al. Preparation, in vitro and in vivo evaluation of algino-pectinate bioadhesive microspheres: An investigation of the effects of polymers using multiple comparison analysis. Acta Pharm 2010;60:255-66.

6. Lehr CM, Bowstra JA, Tukker JJ, et al. Intestinal transit of bioadhesive microspheres in an in situ loop in the rat-A comparative study with copolymers and blends based on poly (acrylic acid). J Control Rel 1990;13:51-62.

7. Sipahigil 0, Gursoy A, Cakalagaoglu F, et al. Release behavior and biocompatibility of drug-loaded $\mathrm{pH}$ sensitive particles. Int $\mathrm{J}$ Pharm 2006;311:130-38.

8. Merchant HA, Shoaib HM, Tazeen J, et al. Once-daily tablet formulation and in vitro release evaluation of cefpodoxime using hydroxypropyl methylcellulose: A technical note. AAPS Pharm Sci Tech 2006;7:78.

9. Bourne DW. Pharmacokinetics. In: Banker GS, Rhodes CT, ed. Modern Pharmaceutics, 4th ed. New York: Marcel Dekker; 2002. pp 67-92.

10. Higuchi T. Mechanism of sustained-action medication. Theoretical analysis of rate of release of solid drugs dispersed in solid matrices. J Pharm Sci 1963;52:1145-9.

11. Hixson AW, Crowell JH. Dependence of reaction velocity upon surface and agita- tion: I-theoretical consideration. Ind Eng Chem 1931;23:923-31.

12. Ritger PL, Peppas NA. A simple equation for description of solute release II. Fickian and anomalous release from swellable devices. J Control Rel 1987;5:37-42.

13. Korsmeyer RW, Gurny R, Docler E, et al. Mechanism of solute release from porous hydrophilic polymers. Int J Pharm 1983;15: 25-35.

14. Shah V, Tsong Y, Sathe P, et al. In vitro dissolution profile comparison-statistics and analysis of the similarity factor, f2. Pharm Res 1998;15:889-96.

15. Winter CA, Risley EA, Nuss GW. Carrageenan induced edema in hind paw of the rat as an assay for anti-inflammatory drugs. Proc Soc Exp Biol Med 1962;111:544-7.

16. Kulkarni SK. Handbook of Experimental Pharmacology. 3rd ed. New Delhi: Vallabh Prakashan; 1999. pp 128-131.

17. Mutalik S, Naha A, Usha AN, et al. Preparation, in vitro, preclinical and clinical evaluations of once daily sustained release tablets of aceclofenac. Arch Pharm Res 2007;30:222-34.

18. Kamal AH, Gohary OM, Hosny EA. Alginate-diltiazem hydrochloride beads optimization of formulation factors, invitro and in-vivo availability. J Microencapsul 2003;20:211-25.

19. Ahrabi SF, Madsen G, Dyrstad K, et al. Development of pectin matrix tablets for colonic delivery of model drug ropivacaine. Eur J Pharm Sci 2000;10:43-52. 